\title{
IN-FLIGHT RADIOMETRIC CALIBRATION OF THE AIRBORNE VISIBLE/INFRARED IMAGING SPECTROMETER (AVIRIS)
}

\begin{abstract}
James. E. Conel, Robert 0. Green, Ronald E. Alley, Carol J. Bruegge, Veronique Carrere, Jack S. Margolis, Gregg Vane, and Thomas G. Chrien Jet Propulsion Laboratory, California Institute of Technology, Pasadena, California 91109
\end{abstract}

Philip N. Slater, Stuart F. Biggar, and Phi1 M. Teillet University of Arizona, Tucson, Arizona 85721

Ray D. Jackson and M. Susan Moran

United States Department of Agriculture, Phoenix, Arizona 85040

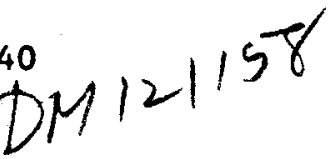

\section{ABSTRACT}

A reflectance-based method was used to provide an analysis of the in-flight radiometric performance of AVIRIS. Field spectral reflectance measurements of the surface and extinction measurements of the atmosphere using solar radiation were used as input to atmospheric radiative transfer calculations. Five separate codes were used in the analysis. Four include multiple scattering, and the computed radiances from these for flight conditions were in good agreement. Code-generated radiances were compared with AVIRIS-predicted radiances based on two laboratory calibrations (pre- and post-season of flight) for a uniform highly reflecting natural dry lake target. For one spectrometer (C), the pre- and post-season calibration factors were found to give identical results, and to be in agreement with the atmospheric models that include multiple scattering. This positive result validates the field and laboratory calibration technique. Results for the other spectrometers (A, B and D) were widely at variance with the models no matter which calibration factors were used. Potential causes of these discrepancies are discussed.

\section{INTRODUCTION}

We present here an updated analysis of the in-flight radiometric performance of the Airborne Visible/Infrared Imaging Spectrometer (AVIRIS) ${ }^{1,2}$. AVIRIS is a scanning imager $(400-2450 \mathrm{~nm})$ that employs four spectrometers connected to common foreoptics by optical fibers. The spectrometers employ linear detector arrays and are labeled A (400-710 nm with 32 detectors), B (680-1280 nm, 64 detectors), C $(1240-1860 \mathrm{~nm}, 64$ detectors $)$, and D (1830-2450 nm, 64 detectors). A test flight was carried out in mid-September 1987, over a field site at Rogers Dry Lake, California (Edwards Air Force Base) with the following objectives: (1) develop radiometric and spectral calibrations for the instrument; (2) determine in-flight signal/noise characteristics; (3) compare various methods of reducing the data to ground reflectance. To support these studies, the following field measurements were made simultaneously with the overflight: (1) atmospheric optical depth using solar radiometers; (2) total precipitable water (in $\mathrm{cm}$ ) with a spectral hygrometer; 
the ratio of direct to diffuse radiation incident at the surface using a hand-held ratioing radiometer $\left(H_{H R R^{3}}\right.$ ). Spectral reflectance factor measurements were made of the bright playa surface using the Portable Instantaneous Display and Analysis Spectrometer (PIDAS ${ }^{4}$ ), a Barnes Modular Multispectral 8-Channel Radiometer (MMR ${ }^{5}$ ) and an Exotech Model $100-\mathrm{AX}$ radiometer ${ }^{6}$.

To meet the first objective we used a surface reflectance-based method ${ }^{6}$ and compared the solar radiance at the instrument reflected from the playa target as determined from a laboratory calibration of AVIRIS ${ }^{7}$, with the radiance predicted from that target according to an atmospheric model. Previously we used the LOWTRAN 6 code $^{8}$ for these comparisons, recognizing by so doing that we could only account for a single order of scattering in the predicted radiance. In the present work, we employed the LOWTRAN 7 code, which provides a description of multiple scattering (with Rayleigh and aerosol contributions) together with gaseous absorption, we also used multiple scattering codes developed by Herman and Browning, and Diner and Martonchik ${ }^{2}$. The latter two codes also account for multiple scattering and absorption effects, but rely on user inputs to quantify these at each wavelength. No spectral gaseous absorption databases are included within the codes themselves.

In addition to incorporation of improved scattering codes in the analysis, we compared the results of pre- and post-flight season laboratory calibrations of the instrument using the Rogers Lake data. Apart from sound procedure, the relevance of this comparison stems from the post-1987 flight season discovery ${ }^{\top}$ of the detachment of optical fibers connecting the foreoptics to spectrometers $A$ and $B$. The point in time of this occurrence during flight operations during the summer of 1987 is not known. But these comparisons, together with a reanalysis of the laboratory radiometric calibration procedure itself, has helped to sort out explanations for the substantially reduced radiometric performance of AVIRIS previously reported?

We also present comparisons of independent atmospheric optical depth and surface reflectance measurements by the Jet Propulsion Laboratory (JPL), University of Arizona (JJA), and United States Department of Agriculture (ISDA) groups. The field data obtained agree closely and serve to reduce or eliminate the possibility that discrepancies between the AVIRIS calibrations were due to errors in the fleld measurements.

\section{TEST SITE AND FIELD MEASUREMENTS}

\subsection{Site, flight and Image data}

Rogers Dry Lake (Lat. $34^{\circ} 55^{\circ} \mathrm{N}$; Long. $117^{\circ} 50^{\circ} \mathrm{W}$ ) is a playa located 104 $\mathrm{km}$ north of Los Angeles, California, at an elevation of $692 \mathrm{~m}$ above sea level. The surface consists of silty mudstone which, from $X$-ray diffraction analysis, contains quartz, plagioclase feldspar, kaolinite, (abundant) analcime, and calcite. The visible and infrared reflectance is however dominated by the presence of hydrated iron oxides that are not detectible in the $X$-ray diffraction data. During the summer and fall months, the playa is dry and the surface is patterned with narrow dessication cracks. Intermittent streams have dissected the eastern half exposing a series of varicolored brown and tan strata beneath the surface layer. Such erosion has lead to broad patchiness in the exposed surface. Nevertheless, large areas of relatively uniform surface properties remain; these constitute the standard targets employed in our studies. 
AVIRIS overflew the test site on September 14, 1987, around 10:20 AM Pacific Standard Time (18:20 hr UT) at an altitude of $20 \mathrm{~km}$ above terrain. AVIRIS has a one-milliradian instantaneous field-of-view and a 30 -degree scan angle, which determines a $20 \mathrm{~m}$ pixel size and $10.5 \mathrm{~km}$ swath width of the ground. The test flight took place under cloud-free, but hazy atmosphere conditions. The calculated visibility was $26 \mathrm{~km}$.

The image data contain periodic noise, and at least three spatially distinct patterns are present. The most prominent of these has a period of about 10.3 ines per cycle $\left(0.097\right.$ line $\left.{ }^{-1}\right)$ normal to the banding which trends at an angle of about $18^{\circ}$ to the scan direction. A second band set has a period 12.8 lines per cycle $(0.78$ line ${ }^{-1}$ ) at an angle of about 65 degrees; the third periodic variation is manifested within the second set with a period of one line per cycle ( 1 line ${ }^{-1}$ ) along the flight direction. A complete analysis of the noise characteristics of the data will be presented elsewhere.

\subsection{Spectral reflectance measurements}

Coincident with the time of aircraft overflight, we measured the spectral reflectance of the playa target with PIDAS and with the broadband MMR and Exotech filter radiometers. PIDAS covers the spectral range $425-2500 \mathrm{~nm}$ with sampling intervals of $0.88 \mathrm{~nm}$ between 450 and $900 \mathrm{~nm}$, and $4.7 \mathrm{~nm}$ between 900 and $2500 \mathrm{~nm}$. The MMR has filters matched to Thematic Mapper (TM) band widths with central wavelengths of $486,571,661,838,1677,2223 \mathrm{~nm}$, and an additional band centered at $1254 \mathrm{~nm}$.

The field sampling strategy employed by the UA and USDA groups has been described in detall by Slater et al. A rectangle $-4 \times 16$ pixels in size (20 m per pixe1) - was marked on the surface, its length being parallel to the flight line. Cross patterns of 16 measurements were made within each pixel, and averages and the scatter in each were computed individually and for the total 1024 measurements. The fleld reference was a $\mathrm{BaSO}_{4}$ panel. These reflectance factor measurements were traceable to the National Bureau of Standards diffuse reflectance standard by calibration with respect to a pressed halon surface ${ }^{2}$. With PIDAS, four measurements were made at the center of each pixel and combined to secure an average froin 256 measurements. In practice, about 50 measurements were lost, and the averages were computed from $200 \mathrm{spectra.} \mathrm{The} \mathrm{fleld} \mathrm{reflectance} \mathrm{standard} \mathrm{was} \mathrm{a}$ portable pressed halon surface prepared to NBS specifications.

Figure 1 shows that there is good agreement between the determinations of the spectral reflectance of the playa target measured by PIDAS and by the MMR. The PIDAS reflectance data depict mean values \pm 1 standard deviation of the observations. The scatter results from at least two sources, real variations in the surface reflectance, and a variation in the number of shadowed cracks present in the spectrometer field-of-view from place to place. The gap in reflectance between 1800 and $1900 \mathrm{~nm}$ arises from saturation of the atmospheric water band over that interval. The jagged spectrum seen beyond $1700 \mathrm{~nm}$ results from noise (since corrected) introduced by the second of two amplifiers covering the infrared spectral region. The higher value at $2220 \mathrm{~nm}$ returned by the MMR is more nearly correct judging by the general concordance between these values and the hemispherical directional reflectance of a surface sample determined with laboratory ratioing spectroradiometers. 


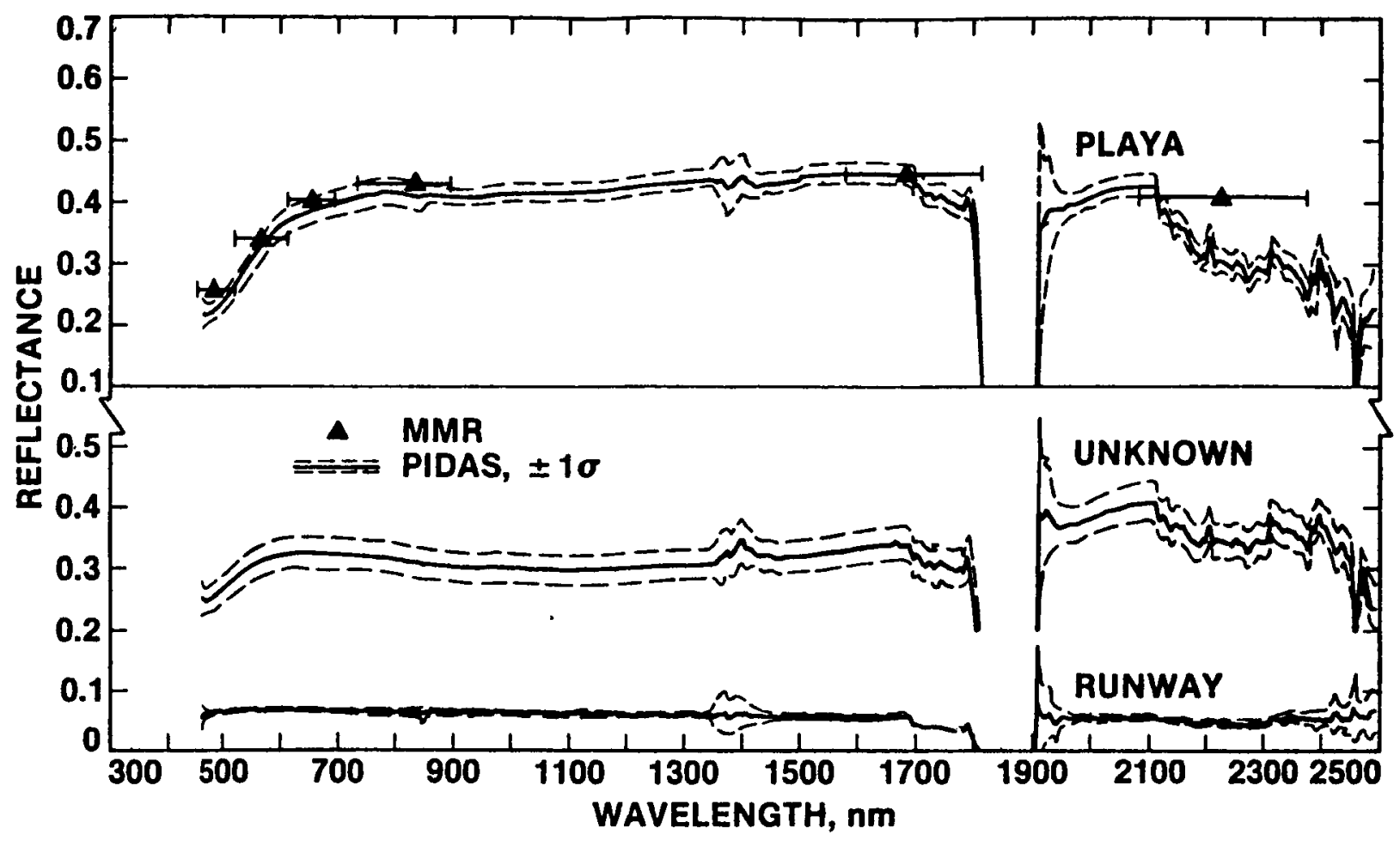

Figure 1 Surface reflectance of playa calibration target on September 14, 1987. Solid line is spectral reflectance given by PIDAS \pm 1 standard deviation, representing an average of 200 spectra. Triangles are reflectance determined over TM bandpasses with MMR, representing averages of about 1500 measurements.

\subsection{Measurement of optical depth}

Measurements of incident solar illumination at ten wavelengths $(370,400$, $440,520,610,670,780,870,940$ and $1010 \mathrm{~nm}$ ) were made with two Reagan-type solar

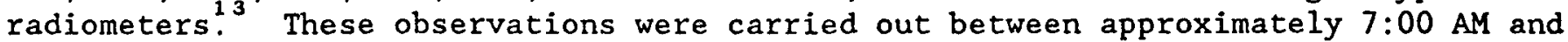
12:30 PM Pacific Standard Time. Optical depths were derived independently from slopes of conventional Langley plots of the solar IR radiance versus the secant of the solar zenith angle. The data for the two Reagan instruments are shown in Figure 2 and compared there to optical depths obtained from the transmittance functions of the standard mid-latitude summer (m1s) LOWTRAN 6 model.

\section{LABORATORY RADIOMETRIC CALIBRATION OF AVIRIS}

\subsection{Definitions and procedure}

The laboratory radiometric calibration of AVIRIS was described in detail by Vane et al. ${ }^{2}$ The purpose of this calibrations was to obtain a set of functional relationships (one for each of 224 detectors) between radiance incident at the instrument, and instrumental output. If $\mathrm{L}$ is the radiance (in $\mu \mathrm{Wcm}^{-2} \mathrm{~nm}^{-1} \mathrm{sr}^{-1}$ ) and DR (digital response) the representation of instrument output, the relationship is

$$
\mathrm{L}=\mathrm{DR} / \mathrm{G}
$$

where $G$ represents a "gain" factor $\left(G^{-1}=\right.$ inverse responsivity $\left.{ }^{14}\right)$. In writing 


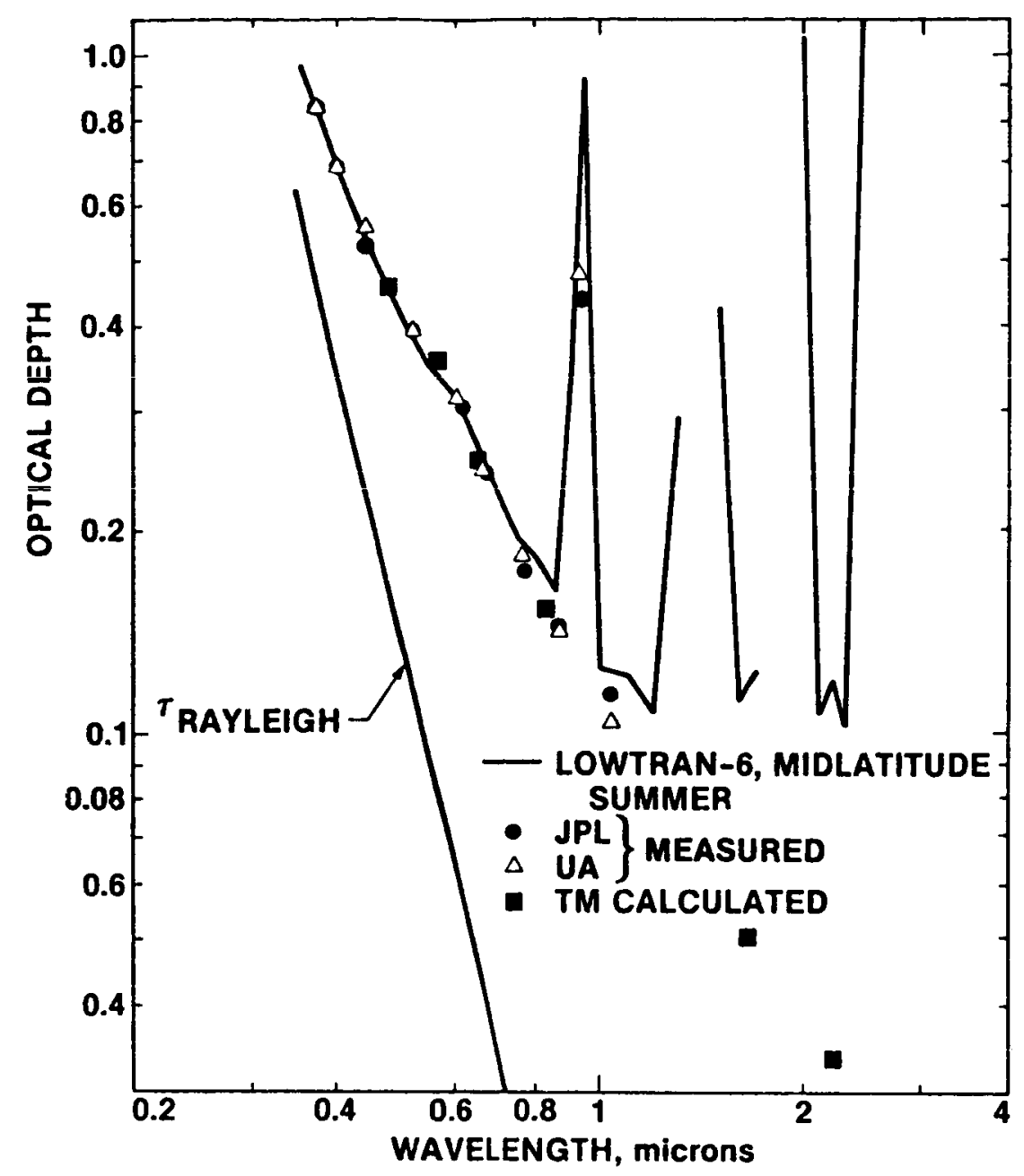

Figure 2 A comparison of optical depths measured by JPL $(\bullet)$ and University of Arizona $(\Delta)$, September 14, 1987, Rogers Dry Lake. Optical depths at TM

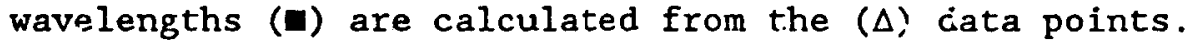

Eqn. (1), it was assumed that detector dark responses were accounted for, i.e., zero instrument output for zero. radiance input.

The procedure for instrument calibration involved four steps: 1) radiometric calibration of a spectroradiometer against a standard lamp, traceable to a National Bureau of Standards lamp; 2) production of light transfer curves (radiance vs. wavelength) for the AVIRIS radiance calibration source (40-inch diameter $\mathrm{BaSO}_{4}$ coated integrating sphere) using a calibrated spectroradiometer; 3) acquisition of AVIRIS DR output files as a function of integrating sphere radiance; and 4) generation of lookup tables of AVIRIS response vs. radiance for each detector at each wavelength. In practice, a linear relationship (Eqn. 1) was assumed and the lookup file generated from a single integrating sphere determination, thus determining a value of $G$. The radiometric calibration converted 10-bit DR values to 32 -bit floating point radiance values.

We briefly recapitulate here the laboratory method used in (1) above because the equation employed by Vane et al. ${ }^{2}$ for calculation of spectral radiance seen by the standard spectroradiometer is incorrect. For its calibration the 
spectroradiometer views a standard halon panel at an angle of $45^{\circ}$. The panel is illuminated at normal incidence by a standard irradiance source at a calibration distance $\mathrm{D}_{\mathrm{CAL}}$ above its surface. The irradiance $\mathrm{E}(\mathrm{CAL})$ at the standard panel is

$$
E(C A L)-E(S T D)\left(D_{S T D} / D_{C A L}\right)^{2}
$$

where $E$ (STD) is the irradiance of the standard lamp provided by the manufacturer measured at the calibration distance $D_{S T D}$. Assuming Lambertian diffuse reflectance from the halon panel with reflectance $\rho$, the radiance $L(C A L)$ uniformly outward from the panel is

$$
L(C A L)=\rho E(C A L) / \pi \text {. }
$$

Combining Eqns. (2) and (3) gives the radiance of the spectroradiometer in terms of the irradiance of the standard lamp. This result is greater than that of Vane et al. ${ }^{2}$ by a factor of $1 / \cos \left(45^{\circ}\right)$, or $\sqrt{2}$. The radiance of the integrating sphere $L_{I S}$ is then determined in terms of the radiance emergent from the halon and the standard lamp irradiance from the relation,

$$
\mathrm{L}_{\mathrm{IS}}-\mathrm{L}(\mathrm{CAL}) A_{S R} \Omega_{S R}\left(\Phi_{S R}(I S) / \Phi_{S R}(\mathrm{CAL})\right) / A_{S R} \Omega_{S R}
$$

where $\Phi_{S R}$ (IS) and $\Phi_{S R}$ (CAL) are respectively the radiant fluxes observed by the spectroradiometer from the integrating sphere and from the calibration source. A and $\Omega_{\mathrm{SR}}$ are the area of the entrance aperture of the spectroradiometer and its solid angular field-of-view. The etendue $A_{S R}{ }^{\Omega} S R$ is of course common to the spectroradiometer for both the integrating sphere path and standard source path, but is included to emphasize that the determination is made from the total radiant flux received in each path.

The absolute accuracy of the radiometric calibration was calculated to be about $\pm 78^{2}$ across the spectral interval 1800-2450 nm, where the response of AVIRIS was observed to be most stable. Over the interval 400 to $1800 \mathrm{~nm}$, additional uncertainties of a few percent are introduced because of thermal distortions (discussed below).

\subsection{Pre- and post-season instrument status and determination of $G$}

The initial laboratory calibration of AVIRIS was carried out in early June, 1987, before the 1987 flight season. During this calibration, it was discovered that the output signal level from the four spectrometers varied with time in the presence of a stable input radiance. The instability was traced to thermally induced distortions from on-off cycling of heaters within the spectrometer barrels. The distortions produced a reduction in signal level without change in wavelength distribution of the energy. The magnitudes of these variations in signal output were: spectrometer A, 3.58; spectrometer B, 7.78; spectrometer C, 4.28; spectrometer $D, 2.48$. During subsequent engineering test flights, variations of twice these magnitudes were observed that also correlated with on-off cycling of the spectrometer heaters, and with distortion of the spectrometer base and instrument rack in-flight.

After termination of the flight season (October, 1987), inspection revealed that the optical fibers connecting spectrometers $A$ and $B$ to the foreoptics had come loose from their mountings. Additionally, a longer wavelength blocking filter had fractured. The exact timing of the mishaps is not known. 
A second post-flight season laboratory calibration of AVIRIS was carried out in October, 1987. In Figure 3, we compared the responsivities $G$ ( $-D R / L$ ) obtained from the pre- and post-season AVIRIS calibrations. The largest changes were seen to have occurred in spectrometers $A$ and $B$ with the post-season numbers smaller by factors varying between 0.36 and 0.91 , compared to pre-season. Spectrometer $C$ proved to be stable. The gain factor for spectrometer $D$ decreased by a factor of about 0.8 .

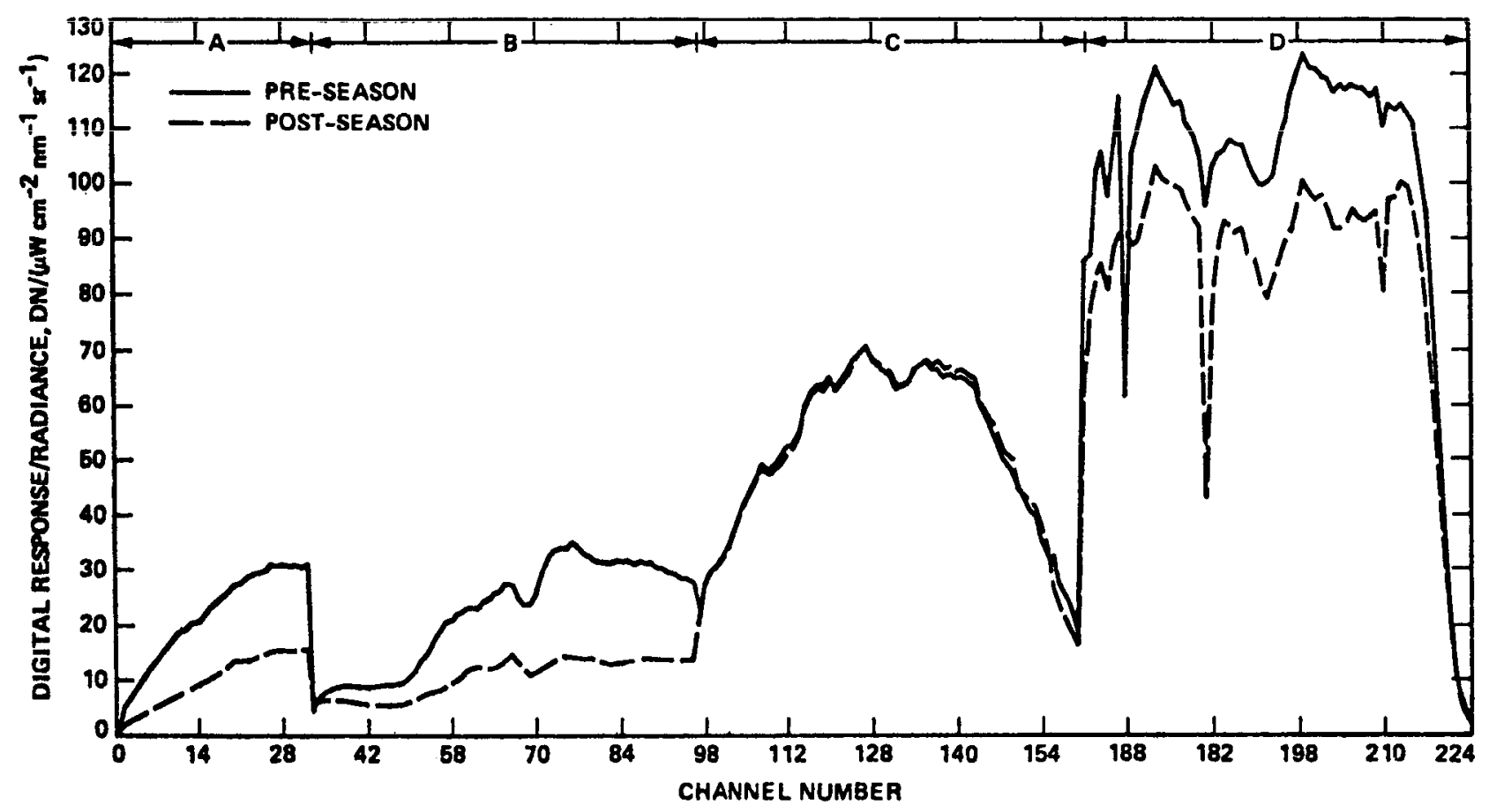

Figure 3 Comparison of the pre- and post-season responsivities (gain factors G) for AVIRIS determined from the laboratory calibrations.

\section{COMPARISON BETWEEN AVIRIS- AND MODEL-GENERATED SOLAR RADIANCES}

An Important test of the validity of the laboratory radiometric calibration for flight conditions is the calculation of solar radiance at the instrument reflected from a target of known reflectance, when account has been taken of the atmosphere, as compared to the radiance predicted from the instrument response. In this section, we present: (1) the responses implied by the two AVIRIS laboratory calfbrations; (2) the results of atmospheric modelling using the measured surface reflectances and atmospheric optical depths; and (3) a comparison of these various results.

4.1 Radiances predicted from AVIRIS using pre- and post-season calibrations

In F1gure 4 are presented the spectral radiances produced for the playa target from the pre- and post-season laboratory radiometric calibrations. For each the \pm 1 standard deviation lines refer to scatter introduced because of natural 


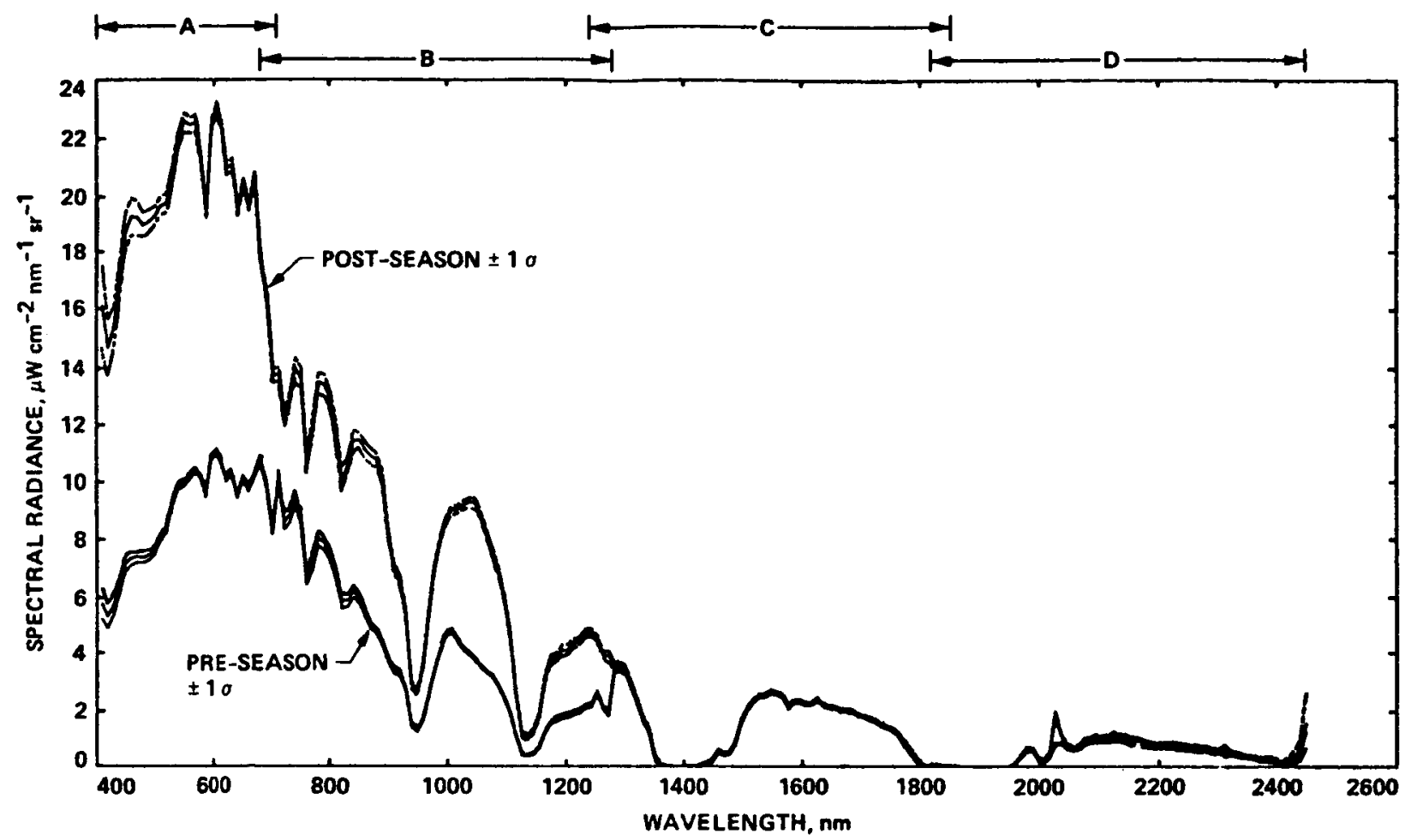

Figure 4 Spectral radiances predicted for the Rogers Day Lake target from AVIRIS from the pre- and post-season radiometric calibrations.

variations in reflectance over the 64 pixels used in the sample and to instrumental noise. As implied by the changes in responsivity shown in Figure 3, the post-season calculated radiance for this target was greater over the spectral regions covered by spectrometers $A, B$ and $D$, and essentially unchanged in the region of $C$.

\subsection{Radiances predicted by atmospheric models}

We have employed four atmospheric radiative transfer (RT) codes in these studies. The results from each are compared below:

(1) LOWTRAN $6^{8}$ calculates atmospheric transmittance and radiance for a given atmospheric path. The code includes molecular absorption and single scattering from aerosols and molecules. The spectral resolution of $20 \mathrm{~cm}^{-1}$ is sufficiently greater than the spectral sampling interval of AVIRIS $(10 \mathrm{~nm})$ to provide a very useful basis for wavelength calibration and effective spectral response for the instrument under flight conditions. The standard mid-latitude summer model was employed, and the geographic and solar conditions were the same as for other codes used, as given in Table 1 .

Single scattering was accounted for using the following equation,

$$
\mathrm{L}_{\text {total }}=\mathrm{L}_{\text {scattered }}+\mathrm{L}_{\text {reflected }}
$$

where $\mathrm{L}_{\text {scattered }}$ is the radiance from single scattering in the atmosphere above any ground elevation, and $\mathrm{L}_{\text {reflected }}$ is the ground-reflected direct radiance reaching the sensor. Two problems exist with the single scattering option in LOWTRAN 6 . 
First, only a single target reflectance is accepted at all wavelengths in the unmodified code. We modified the program to allow for ground reflectance that varied with wavelength as given by PIDAS. Second, the program does not compute ground reflected radiance unless the target is at sea level. To circumvent this difficulty, the downward and upward transmitted parts from the target elevation were computed separately, and multiplied by the surface reflectance. The equation is

$$
\mathrm{L}_{\text {reflected }}=\left(\mathrm{E}_{\rho_{0}} / \pi\right) \mathrm{T}_{\mathrm{dn}} \mathrm{T}_{\text {up }} \mathrm{R}_{\text {PIDAS }}
$$

where $E_{\odot}$ - exoatmospheric solar irradiance, $\mu_{0}$ - cosine of the solar zenith angle, $\mathrm{T}_{\mathrm{dn}}$ - transmittance of downward path, $\mathrm{T}_{\mathrm{up}}=$ transmittance of upward path, and $\mathrm{R}_{\text {PIDAS }}$ is the reflectance of the (horizontal) surface returned by PIDAS.

(2) The principal improvement provided by the LOWTRAN $7^{\circ}$ code, from our standpoint, is the inclusion of multiple scattering, although it has not yet proved possible to modify the program to account for ground reflectance at any elevation except sea level. This code has been changed to account for variable surface reflectance as given by PIDAS.

(3) The UA RT code by Herman and Browning ${ }^{10}$ has been used extensively in the inflight calibration of Landsat providing internally consistent results to within $2.58^{15}$. The code uses Mie theory to compute aerosol scattering functions for a specified size distribution, and the Gauss-Seidel iterative technique to solve the equation of radiative transfer. The aerosol phase function is sampled at discrete angular intervals.

(4) The $5 \mathrm{~S}$ code of Tanré et al. ${ }^{16}$ was modified at the University of Arizona to allow user specification of terrain elevation and sensor altitude, including other changes. The 5S code makes extensive use of analytical expressions and preselected atmospheric models, resulting in a very short execution time. The code has proven to be significantly more accurate than models with fast or moderate execution times (Royer, et $a 1^{17}$ ).

(5) The JPL code ${ }^{11}$ also computes aerosol scattering functions from Mie theory and employs the Gauss-Seidel method, but traces spatial Fourier components of the radiation field, and represents the aerosol phase function as a 24 -term Legendre series. The JPL code is believed, in theory, to have the same degree of certainty as the UA code, but has only recently been tested against field data.

The results of calculations for these five models are given in Figure 5 . Vertical bars on the JPL model points represent approximately the variation in calculated radiance from the variation in surface reflectance as determined with PIDAS (Figure 1). The spectral radiance generated by LOWTRAN 6 and 7 were for the standard mid-latitude summer model ${ }^{8}$. The spectral radiance generated by the JPL, UA and $5 \mathrm{~S}$ codes were for the geographic, solar and atmospheric conditions summarized in Table 1. Note that the LOWTRAN 7 result refers to an atmospheric path from Sun-tosea level to an altitude of $20 \mathrm{~km}$. Removing the lower $690 \mathrm{~m}$ of atmosphere, corresponding to the actual elevation of Rogers Lake, can be expected to increase the computed radiance somewhat, because of decreased attenuation, but to decrease the scattered component because of the reduction in scattering volume. The net result might be expected to resemble more closely the Herman-Browning radiance, since this code accounts for molecular absorption through the $5 \mathrm{~s}$ code, at the proper elevation. The LOWTRAN 6 result, which represents the sum of directly transmitted radiation reflected by the ground and singly scattered radiation in the 


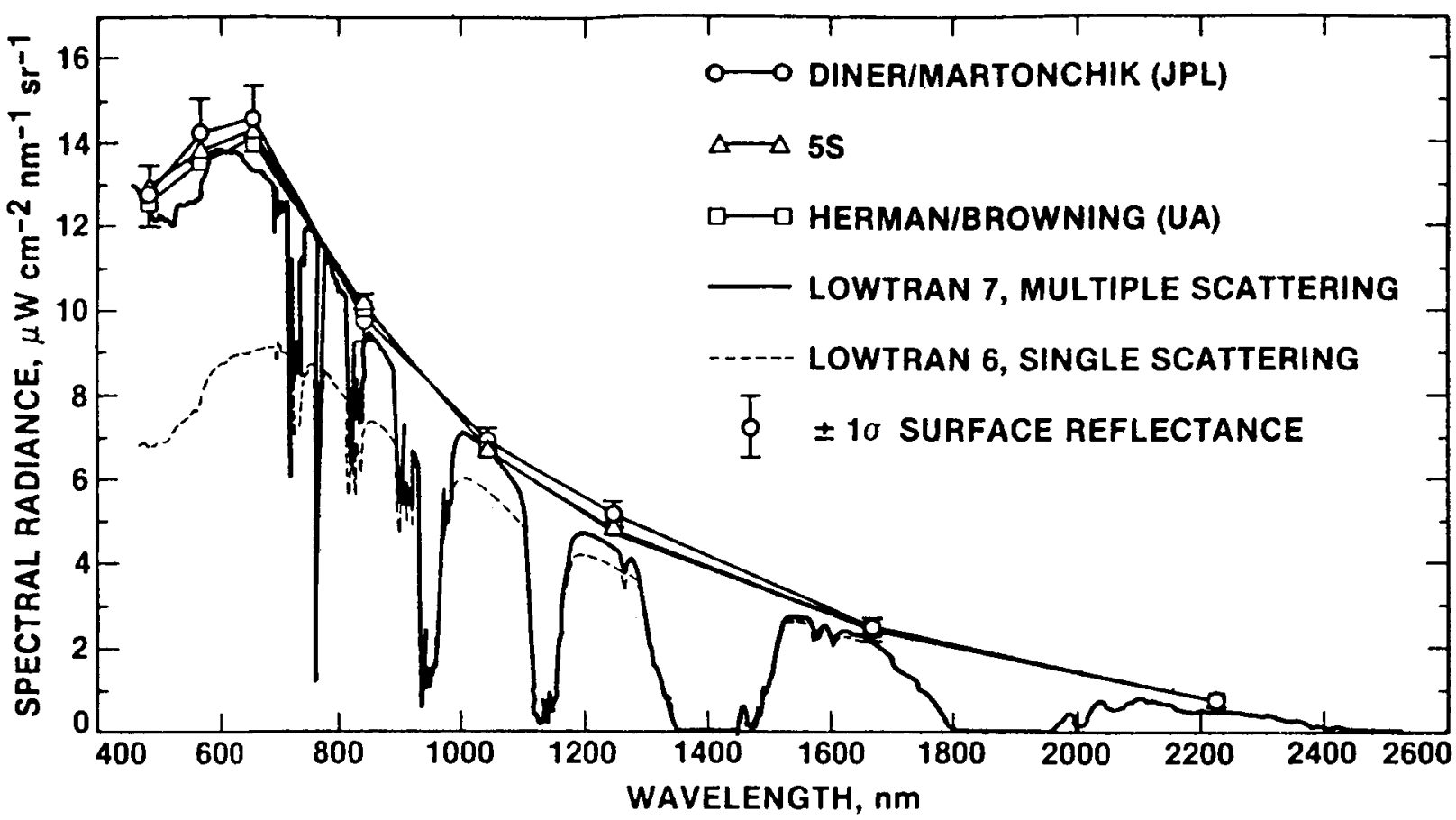

Figure 5 Comparison of radiances generated by atmospheric RT models: LOWTRAN 6, single scattering; (2) LOWTRAN 7, multiple scattering; UA code; (4) $5 \mathrm{~S}$ code; and (5) JPL code.

TABLE 1

\begin{tabular}{|c|c|c|c|c|c|c|c|c|}
\hline \multicolumn{9}{|c|}{$\begin{array}{l}\text { MODEL CONDITIONS EMPLOYED WITH UA, 5S AND JPL RT CODES } \\
\text { FOR ROGERS ORY LAKE, CALIFORNIA SEPTEMBER 14, } 1987\end{array}$} \\
\hline & \multicolumn{2}{|c|}{$\begin{array}{l}\text { SOLAR ZENITH ANGLE: } 37.3 \\
\text { SOLAR AZIMUTH ANGLE: } 142.9 \\
\text { SOLAR DISTANCE, AU: } 1.0058 \\
\text { LATITUDE: } 34059.7^{\circ} \\
\text { LONGITUDE: } 117052.4^{\prime} \\
\text { ELEVATION: } 694 \mathrm{~m} 2276^{\prime} \\
\text { AIRCRAFT ALT.: } 20 \mathrm{~km} 65620^{\prime} \\
\text { TIME OF OVERPASS: } 18: 21 \text { UT } \\
\text { CALCULATED VISIBILITY: } 26 \mathrm{~km}\end{array}$} & & \multicolumn{4}{|c|}{$\begin{array}{l}\text { JUNGE SIZE DISTRIBUTION: } 3.46 \\
\text { AEROSOL SIZE RANGE: } 0.02-5.02 \mu \mathrm{m} \\
\text { REFRACTIVE INDEX: } 1.54-0.01 \mathrm{i} \\
\text { PRESSURE: } 920.4 \mathrm{mb} \\
\text { TEMPERATURE: } 21{ }^{\circ} \mathrm{C} \\
\text { H2 CONTENT: } 0.729 \mathrm{~g} / \mathrm{cm} 2 / \mathrm{km} \\
\text { INTEGRATED PATH } \mathrm{H} 20: 1.76 \mathrm{~g} / \mathrm{cm} 2 \\
\text { OZONE CONTENT: } 0.376 \mathrm{~cm}-\mathrm{atm} \\
\text { NADIR VIEWING ANGLE: }<5^{\circ}\end{array}$} & \multirow[b]{2}{*}{7} \\
\hline THEMATIC MAPPER BAND & 1 & 2 & 3 & 4 & & & 5 & \\
\hline \multirow{6}{*}{$\begin{array}{l}\text { CENTRAL WAVELENGTH }(\mathrm{nm}) \\
\text { OPTICAL DEPTH } \\
\text { AEROSOL } \\
\text { RAYLEIGH } \\
\text { GAS TRANSMITTANCE, (5S) } \\
\text { SURFACE REFLECTANCE } \\
\text { SOLAR IRRAO.,Wm- }{ }^{-2} \mathrm{~m}^{-1} \\
\text { NORMALIZED CODE RAD. } 11 \\
\text { RADIANCE, } \mathrm{Wm}^{-2} \mathrm{~mm}^{-1} \mathrm{sr}^{-1}\end{array}$} & 486.3 & 570.6 & 660.7 & $8 ? \cap 9$ & $1050^{3}$ & $1250^{a}$ & 1677.0 & 2223.0 \\
\hline & 0.299 & 0.237 & 0.191 & 0.135 & 0.0958 & 0.0706 & 0.049 & 0.032 \\
\hline & 0.148 & 0.077 & 0.042 & 0.016 & 0.0065 & 0.0032 & 0.0010 & 0.0003 \\
\hline & $\begin{array}{r}0.988 \\
0.253\end{array}$ & $\begin{array}{l}0.920 \\
0.335\end{array}$ & $\begin{array}{l}0.962 \\
0.395\end{array}$ & $\begin{array}{l}0.964 \\
0.430\end{array}$ & $\begin{array}{l}0.999 \\
0.416\end{array}$ & & $\begin{array}{l}0.990 \\
0.446\end{array}$ & $\begin{array}{l}0.979 \\
0.409\end{array}$ \\
\hline & 1883.84 & 1799.95 & 1533.35 & 1011.00 & 658.19 & 464.49 & 221.13 & 71.26 \\
\hline & .06797 & .07985 & .09622 & .1076 & 0.1046 & 0.1082 & .1120 & .1029 \\
\hline UA $10^{\circ}$ & 126.3 & 135.6 & 140.6 & 101.6 & 66.9 & 48.6 & 24.2 & 7.1 \\
\hline $5 s^{16}$ & 128.7 & 139.3 & 144.1 & 103.0 & 67.2 & 48.7 & 24.3 & 7.2 \\
\hline JPL 11 & 128.0 & 143.7 & 147.5 & 1002 & 68.69 & 49.86 & 24.2 & 7.0 \\
\hline PERCENT DIFFERENCE & & & & & & & & \\
\hline \multirow{2}{*}{$\begin{array}{l}100 \times(J P L-U A) / J P L \\
100 \times(J P L-5 S) / J P L\end{array}$} & 1.4 & 5.6 & 4.7 & -1.4 & 2.6 & 2.5 & 0.0 & -1.4 \\
\hline & -.52 & 3.8 & 2.3 & -2.8 & 2.2 & 2.3 & -0.3 & -2.9 \\
\hline $100 \times(5 S-U A) / U A$ & 1.9 & 2.7 & 2.5 & 1.4 & 0.4 & 0.2 & 0.4 & 1.4 \\
\hline
\end{tabular}

a MONOCHROMATIC VALUES

b CAL CULATED FROM A AT CODE OF TAURE Et al. 16 USED HERE FOR DETERMINING GASEOUS TRANSMITTANCES 
atmosphere is about $35-408$ lower at shorter wavelengths than the results from the other codes. The reasons are twofold, LOWTRAN 6 ignores the diffuse irradiance of the sky on the target and the upward atmospheric path radiance. The distinction between the results for LOWTRAN 6 and LOW'RAN 7 essentially disappears it wavelengths greater than about $1300 \mathrm{~nm}$.

The JPL, UA, and $5 \mathrm{~S}$ models have been exercised at the TM band wavelengths only. The numerical differences in output for these three models are summarized in Table 1. In general the differences are greatest in the region of strongest scattering and may arise in the method of describing the phase function. In particular, for the Herman-Browning and JPL codes, the differences disappear for the case of a purely Rayleigh atmosphere ( $\mathrm{J}$. Martonchik, personal comm.). Close agreement is also found between the continuum LOWTRAN 7 radiance and the model-computed radiance in the TM bands. A better overall fit between these envelopes could be achieved with with closer spacing of the computed points. Two additional points at 1050 and $1250 \mathrm{~nm}$ have been added to realize this in part.

\subsection{Comparison of AVIRIS-generated and model-generated radiances}

The AVIRIS-generated radiance for the playa target using the pre- and postseason gain factors is compared to the three model-generated spectral radiance Iistributio:as in Figure 6. To be dafinite in the comparison, we will sega-d the UA, $5 S$, and JPL codes as more accurately describing the radiance to be expected in $T M$ bands $1-4$ (spectrometers $A$ and $B$ ) from a perfectly functioning and perfectly calibrated instrument because, as we have mentioned, the LOWTRAN 7 simulation does not account properly for the actual elevation of the site. In bands 5 and 7 (spectrometers C and D), atmospheric scattering is diminished as shown in Figure 5, and we can regard comparison with the LOWTPAN 7 model in a better light. The

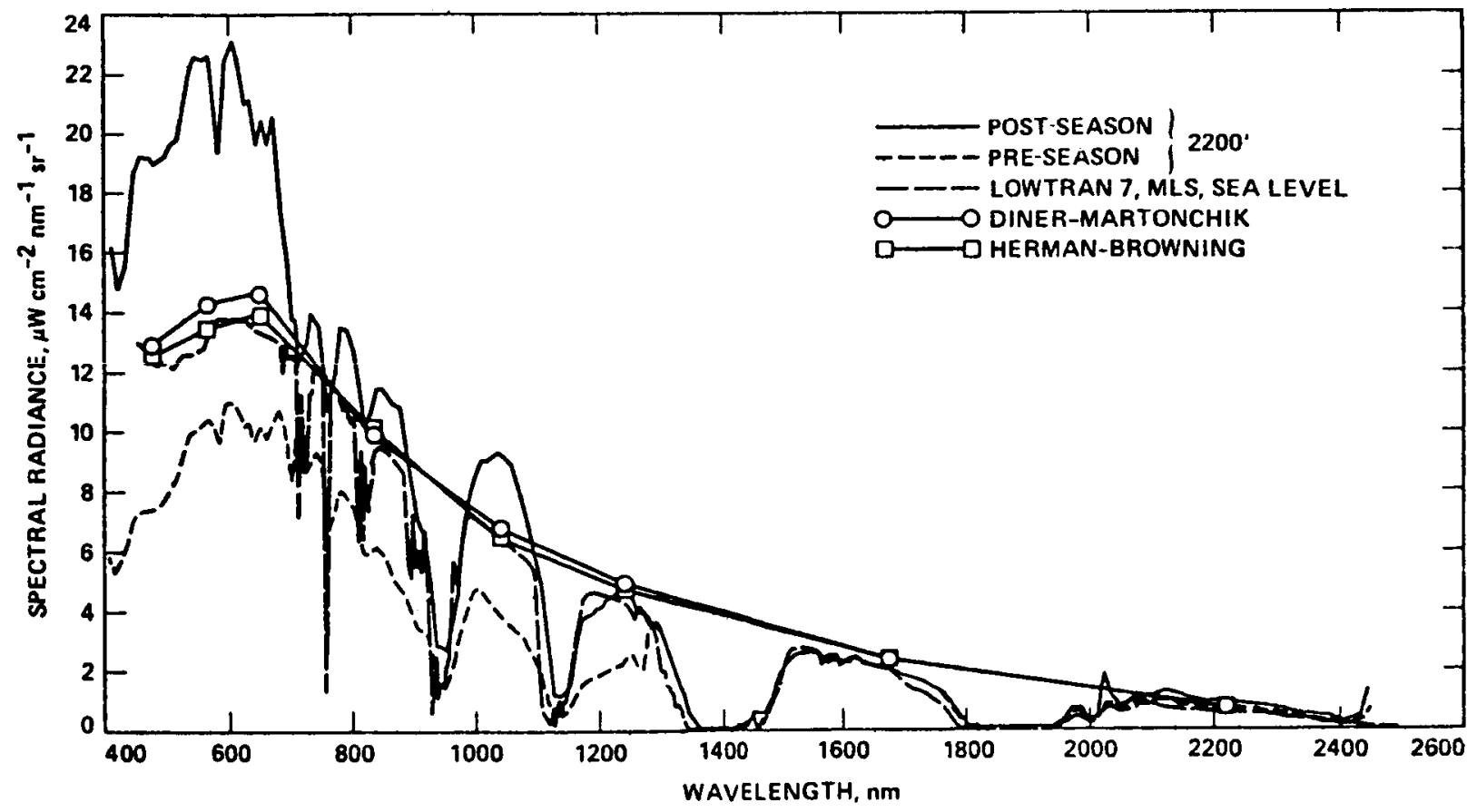

Figure 6 Comparison of RT code results with radiance for the playa target as determined from AVIRIS according to the pre- and post-season radiometric calibrations. 
differences between observed and the JPL- and UA-modelled radiances at TM band wavelengths, where these code radiances were unambiguously determined, are given in Table 2 .

TABLE 2

Comparison (in 8 ) of observed and modelled radiances at wavelengths of TM bands. $(+)$ or $(-)$ values designate observed radiance greater or less than $q$ of the model radiance. (A) indicates TM band falls within region of spectrometer $A$, etc.

\begin{tabular}{|c|c|c|c|c|}
\hline \multicolumn{3}{|c|}{ Pre-season } & \multicolumn{2}{|c|}{ Post-season } \\
\hline Band & JPL & UA & JPL & UA \\
\hline 1 (A) & -43 & -40 & +47 & +52 \\
\hline $2(\mathrm{~A})$ & -27 & -23 & +58 & +67 \\
\hline $3(\mathrm{~A})$ & -32 & -27 & +40 & +47 \\
\hline 4 (B) & -37 & -41 & +13 & +12 \\
\hline 5 (C) & --15 & -.15 & --15 & --15 \\
\hline 7 (D) & 0 & 0 & -+30 & -+30 \\
\hline
\end{tabular}

The comparison with LOWTRAN 7 is given in Figure 7. Here, for spectrometer $C$, the agreement between AVIRIS-derived and model radiance in the continuum region is within (-)58, for both pre- and post-season calibrations. For spectrometer $D$, the pre-season result is about 258 higher and the post-season 50-758 higher than the model. The result for spectrometer $C$ is encouraging and leads us to believe in the general correctness of the laboratory and model comparisons attempted here, despite unfavorable comparisons in the other spectrometers.

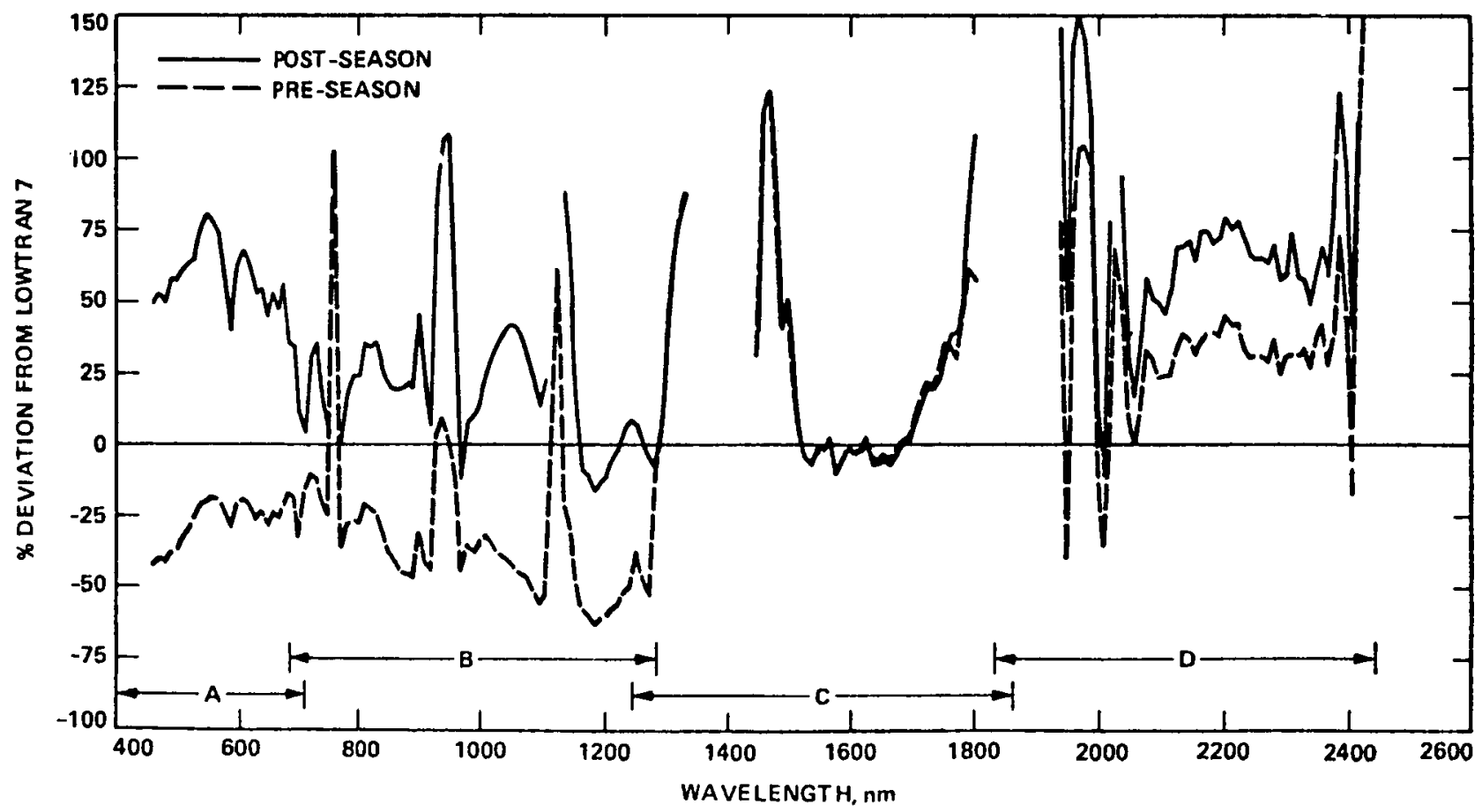

Figure 7 Percentage difference 100 (LOWTRAN-AVIRIS)/LOWTRAN for the playa target and pre- and post-season calibrations. Code used is LOWTRAN 7. 
The region 450-1050 $\mathrm{nm}$, covering all of the $A$ and part of the $B$ region is presented scale-expanded in Figure 8 and compared to the LOWTRAN 7 result which provides the spectral continuity required to interpret (in detail) the AVIRIS spectrum. Possibly excepting the concave upward portion of the observed AVIRIS spectrum between $450-550 \mathrm{~nm}$, which may represent the $\mathrm{Fe}^{+3}$ band seen in the playa reflectance (Figure 1), the additional features present were introduced by the instrument or are noise. Compare this result with that reported by Vane ${ }^{18}$ (his Figure 6) at Stonewall Playa, Nevada, in which similar features are present. Note also the prominent discontinuity near $700 \mathrm{~nm}$ introduced between the spectral regions of $A$ and $B$ by the post-season calibration.

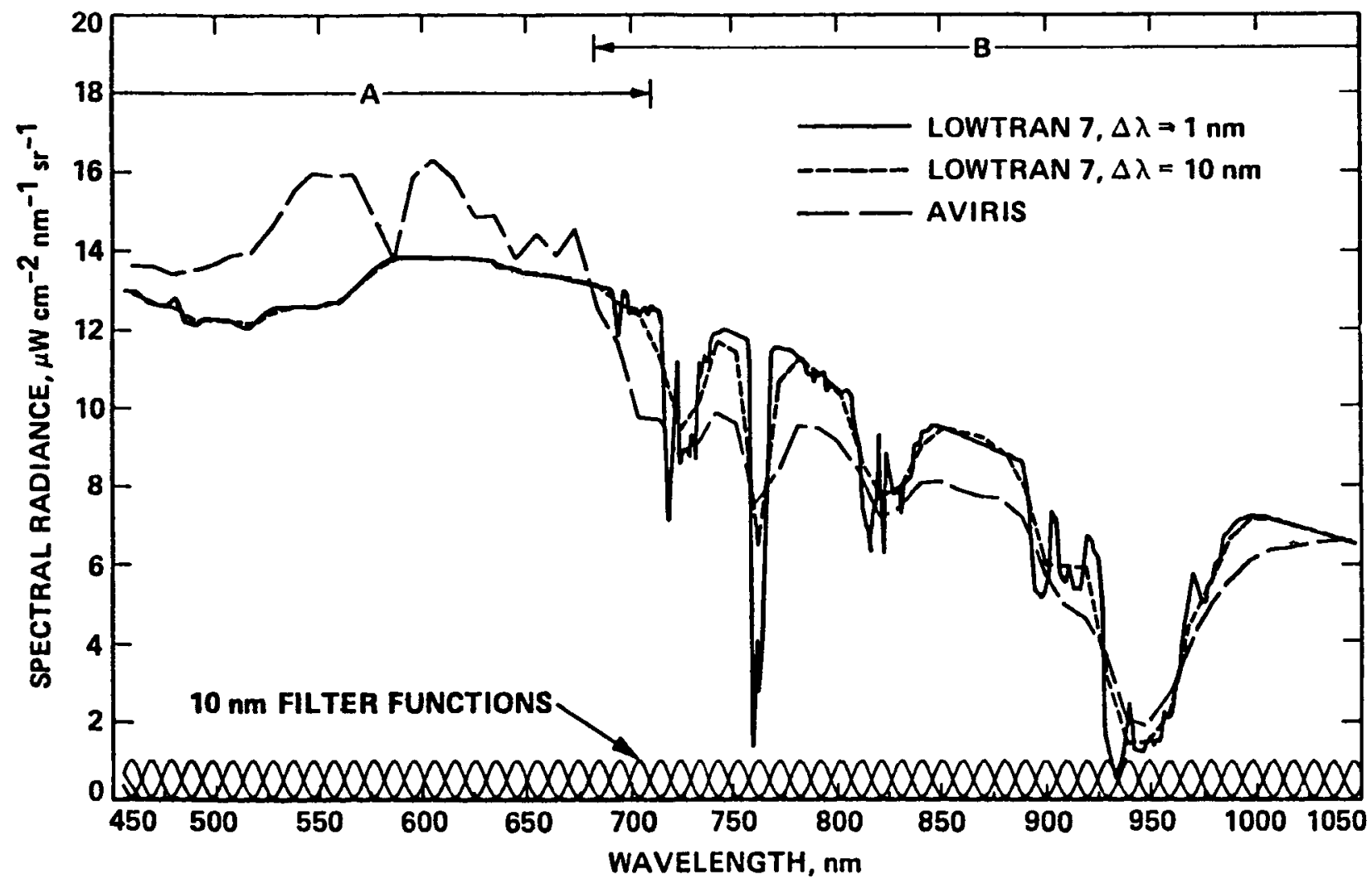

Figure 8 Comparison of LOWTRAN 7 and AVIRIS-predicted radiances for the spectral region 450-1050 $\mathrm{nm}$. The degraded LOWTRAN spectrum calculated from Eqn (7) using FWHM $\Delta \lambda=9.58 \mathrm{~nm}$ in Eqn (8). Post-season calibration.

\section{EFFECTIVE IN-FLIGHT SPECTRAL RESOLUTION}

We can use the AVIRIS spectra of Figures 6 and 8 to provide estimates of the effective in-flight spectral "resolution", and by inference the spectral sampling interval. By spectral resolution, we mean the detection of separate radiance minima associated with neighboring absorption bands, arising, in this case, in the atmosphere. The spectral sampling interval is obtained qualitatively by dividing the wavelength interval covered by each spectrometer by the number of detectors covering the interval. 
An improved evaluation of the spectral sampling properties of AVIRIS can be obtained by examining the spectral response function. For each detector located provisionally at wavelength $\lambda_{i}$, the signal $s\left(\lambda_{i}\right)$ generated by the incident spectrum $\mathrm{L}(\lambda)$ is

$$
s\left(\lambda_{i}\right)=\int_{0}^{\infty} f\left(\lambda_{i}-\lambda\right) L(\lambda) d \lambda
$$

where $f\left(\lambda_{i}-\lambda\right)$ is the spectral response or spread function of the system at $\lambda_{i}$ from the radiance at wavelength $\lambda$. In practice, this is evaluated by restricting $L(\lambda)$ to a narrow band of wavelengths $\Delta \lambda$ at successive wavelengths $\lambda^{\prime}$ to secure approximately

$$
s\left(\lambda_{i}-\lambda^{\prime}\right) \approx f\left(\lambda_{i}-\lambda^{\prime}\right) L\left(\lambda^{\circ}\right) \Delta \lambda
$$

The spectral response curves for a number of AVIRIS detectors have been determined by vane et al. ${ }^{2}$ using $\Delta \lambda=1 \mathrm{~nm}$. The function

$$
f(x)=\exp \left(-h^{2} x^{2}\right)
$$

proves to be a good representation for the normalized response $s\left(\lambda_{j}-\lambda\right) / L(\lambda) \Delta \lambda$ (Figure 9). The central wavelength of the channel is taken to be the maximum of $f(x)$, thus fixing $\lambda_{i}$, and the full width $\Delta \lambda_{i}$ at half maximum height (FWHM) as the effective channel spectra width of sampling interval. This gives $h=1.665 / \Delta \lambda_{i}$. The spectral sampling intervals for AVIRIS for all spectrometers have been determined by Vane et $a 1 .^{2}$ as follows: spectrometer A, $10.0 \mathrm{~nm}$, spectrometer B, 9.58 $\mathrm{nm}$, spectrometer $C, 9.86 \mathrm{~nm}$; spectrometer $D, 9.85 \mathrm{~nm}$.

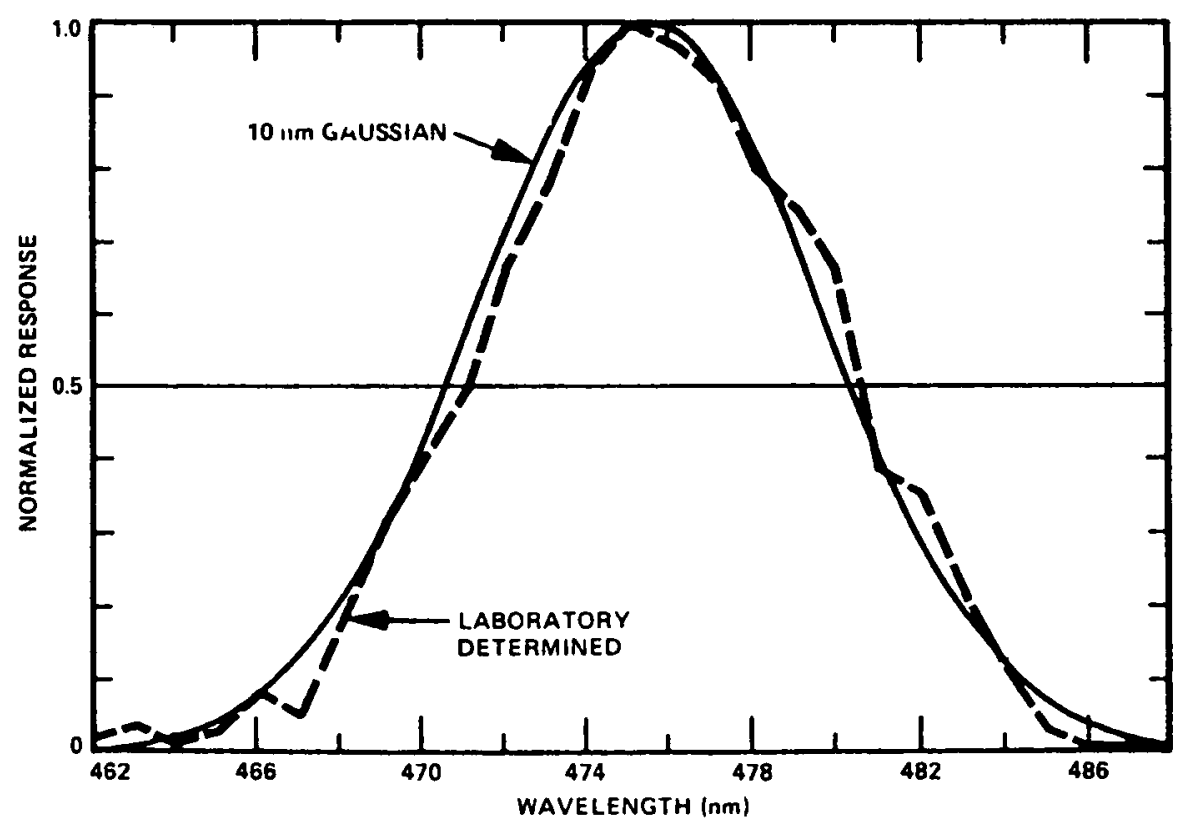

Figure 9 Comparison of laboratory-measured spectral response with approximation of the single-channel normalized spectral response by the function $f(x)=\exp \left(-h^{2} x^{2}\right)$ (smooth curve). 
In principle, the resolution is determined from the sampling interval and Nyquist's sampling theorem. If the frequency of sampling is $1 / \delta \lambda_{\mathrm{s}} \mathrm{nm}^{-1}$, then the sampling interval $\Delta_{s}=1 / 2 \delta \lambda_{s}$. Thus, for $\delta \lambda_{s}=10 \mathrm{~nm}, \Delta_{s}=20 \mathrm{~nm}$; that is, narrow bands in adjacent channels will produce a single minimum in radiance and are not distinguished unless separated by $\geq 20 \mathrm{~nm}$.

We now use these results to examine the implied resolution throughout the spectrum. From Figure 6, at $2050 \mathrm{~nm}$ (spectrometer D), the pair of $\mathrm{CO}_{2}$ bands are separated by $50 \mathrm{~nm}$, and are clearly resolved, thus establishing a resolution $<50 \mathrm{~nm}$ for that spectrometer. At $1600 \mathrm{~nm}$ (spectrometer $\mathrm{C}$ ), the atmospheric $\mathrm{CO}_{2}$ bands there are separated by $30 \mathrm{~nm}$ and are also resolved.

An improved description of the in-flight spectral resolution is possible taking account of the functional form of the spectral response curves, Eqn (9). For AVIRIS, a single detector sees a signal that is represented by Eqn ( 7 ), which can be used with Eqn (9) to calculate a degraded full-resolution LOWTRAN 7 equal to that of AVIRIS. By comparing the degraded LOWTRAN spectrum to the observed AVIRIS spectrum and using $h$ as a variable parameter the effective AVIRIS spectral resolution can be deduced. This comparison is shown in Figure 8 using FWHM $=10 \mathrm{~nm}(\mathrm{~h}=0.1665)$, which represents the expected AVIRIS spectrum if the instrument were actually sampling at the laboratory-determined estimated sampling interval. A better match (Figure 10) is provided by doubling the width of the Figure 9 spectral response curve so that the full sampling width at half-maximum is $20 \mathrm{~nm}$. This is in accord

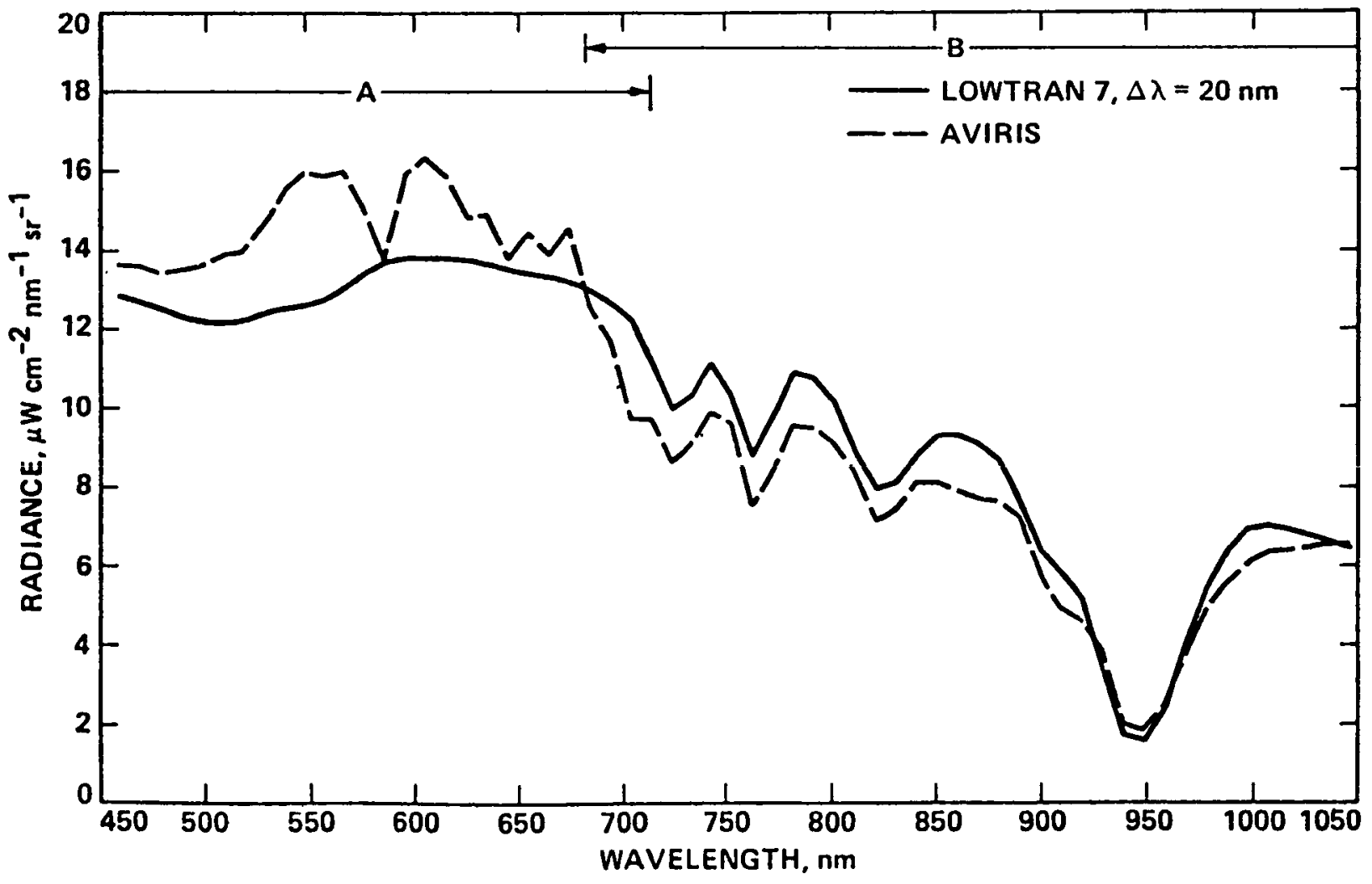

Figure 10 Comparison of the observed AVIRIS spectrum and LOWTRAN 7 spectrum degraded using FWHM $\Delta \lambda=20 \mathrm{~nm}$ in Eqn (8). Post-season calibration. 
with the post-season spectral calibration of AVIRIS, which revealed that, because of the detachment of optical fibers in spectrometers $A$ and $B$ and the resulting defocussing, the spectral FWHM of these two spectrometers was 18-20 nm compared to 9$10 \mathrm{~nm}$ in the pre-season calibration. Spectrometers $C$ and $D$ were found to have remained unchanged.

\section{SUMMARY}

Data from an AVIRIS overflight of a field test site at Rogers Dry Lake, California have been analyzed to characterize the in-flight radiometric and spectral performance of the instrument. The combined field data sets of the UA, USDA and JPL groups, consisting of spectral reflectance observations of the playa and optical depth measurements of the atmosphere, are presented. Results of the measurement programs agreed closely (a few percent for reflectance, 18 for optical depth determinations). Results of two laboratory radiometric calibrations of AVIRIS, preand post-season are presented. Significant differences in gain factors were found between the two calibrations, varying from reductions of as much as a factor of 2.8 in performance (spectrometer A) to essential stability (spectrometer C). Employing a reflectance-based method, we compared the AVIRIS-generated response to five separate atmospheric RT models. Reasonable and encouraging agreement was found between the irstrument-produced radiance using the post-season calibration data, and the three multiple scattering RT models employed, particularly for spectrometer $C$. A scenario that may explain much of the variable behavior of the other spectrometer is as follows: (1) instrument was calibrated pre-season; (2) optical fibers detached during flight season prior to September 14 calibration flight; (3) instrument was re-calibrated post-season with fibers detached but not necessarily in positions occupied during the September 14 calibration flight. While the fiber detachment problem may partly account for the variable performance of AVIRIS relative to that expected, a complete story must include the effects of in-flight thermal and mechanical distortion, since the flight environment is drastically different from that of the laboratory. There seems to be no way of separating these effects for the past data sets because AVIRIS has since been refurbished. We must therefore rely on future test flights to explore such questions.

\section{ACKNOWLEDGMENTS}

We thank Eric Laue and John Appleby of JPL for their assistance. Research described here was carried out by Jet Propulsion Laboratory, California Institute of Technology, under contract with the National Aeronautics and Space Administration.

\section{REFERENCES}

1. Vane, G. (ed.) (1987), Airborne Visible/Infrared Imaging Spectrometer (AVIRIS): A description of the sensor, ground data processing facility, laboratory calibration and first results. JPL Publication 87-38, Jet Propulsion Laboratory, Pasadena, CA, $97 \mathrm{pp}$.

2. Vane, G., T. G. Chrien, E. A. Miller and J. H. Reimer (1987), Spectral and radiometric calibration of the Airborne Visible/Infrared Imaging Spectrometer, Proceedings of SPIE Conference on Imaging Spectroscopy iI (San Diego, CA, 20-21 August, 1987), 834, 91-105.

3. Whitney, G., M. Abrams and A. F. H. Goetz (1983), Mineral discrimination using a portable ratio-determining radiometer, Econ. Geol., 78(4), 688-6.98. 
4. Goetz, A. F. H. (1987), The Portable Instant Display and Analysis Spectrometer (PIDAS), in Proceedings of the third Airborne Imaging Spectrometer data analysis workshop (G. Vane, ed.), JPL Publication 87-30, Jet Propulsion Laboratory, Pasadena, CA, 8-17.

5. Robinson, B. F., M. E. Bauer, D. P. Dewitt, L. F. Silva and V. C. Vanderbilt (1979), Multiband radiometer for field research, SPIE, 196, 8-155.

6. Slater, P. N., S. F. Biggar, R. G. Holm, R. D. Jackson, Y. Mao, M. S. Moran, J. M. Palmer and B. Yuan (1987), Reflectance- and radiance-based methods for the in-flight absolute calibration of multispectral sensors, Rem. Sens. Envir., 22, 11-37.

7. Conel, J. E., G. Vane, R. O. Green, R. E. Alley, V. Carrere, A. Gabell, and C. J. Bruegge (1988), Airborne Visible/Infrared Imaging Spectrometer (AVIRIS): In-Flight radiometric calibration and the determination of surface reflectance, presented at $4^{\mathrm{e}}$ Colloque International signatures Spectrales D'Objets en Teledetection (Aussois, France, 18-22 January).

8. Kneizys, F. X., E. P. Shettle, W. O. Gallery, J. H. Chetwynd, Jr., L. W. Abrew, J. E. A. Shelby, S. A. Clough and R. W. Fenn (1983), Atmospheric transmittance/radiance: Computer code LOWTRAN 6, AFGL-TR-83-0187, AFGL Hanscom AFB, MA, 200 Pp.

9. Kneizys, F. X., E. P. Shettle, G. P. Anderson, L. W. Abrew, J. H. Chetwynd, J. E. A. Shelby, S. A. Clough and W. O. Gallery (198E;, "Atmospheric transmittance/radiance: Computer code LOWTRAN 7 (in press).

10. Herman, B. M. and S. R. Browning (1975), The effect of aerosols on the Earthatmosphere albedo, J. Atmos. Sci., 32, 1430-1445.

11. Diner, D. J. and J. V. Martonchik (1984), Atmospheric transfer of radiation above an inhomogeneous non-Lambertian reflective ground: I. Theory, $J$. Quant. Spectros. Radiat. Transfer., 31, 97-125.

12. Jackson, R. D., M. S. Moran, P. N. Slater and S. F. Bigger (1987), "Field calibration of reference reflectance panels", Rem. Sens. Env., 22, 145158 .

13. Shaw, G. E., J. A. Reagan and B. M. Herman (1973), Investigations of atmospheric extinction using direct solar radiation measurements made with a multiple wavelength radiometer, J. App1. Meteorol., 12, 374-380.

14. Wyatt, C. L. (1978), Radiometric calibration: theory and methods, Academic Press, New York, 200 Pp.

15. Slater, P. N., S. F. Bigger, R. G. Holm, R. D. Jackson, Y. Mao, M. S. Moran, J. M. Palmer and B. Yuan (1986), Absolute radiometric calibration of the Thematic Mapper, SPIE, 660, 2-8.

16. Tanré, D., C. Deroo, P. Duhaut, M. Herman, J. J. Morcrette, J. Perbos and P. Y. Dischamps (1985), "Effets atmosphériques en télédétection-logical de simulation du signal satellitaire dans le spectra solaire", Proc. Third Int. Colloq. on Spectral Signatures of objects in Remote Sensing, ESA SP247, pp. 315-319.

17. Royer, A., N.T. O'Nei11, A. Davis, and L. Hubert (1988), Comparison of radiative transfer models used to determine atmospheric optical parameters from space, $S P I E, 928$, in press.

18. Vane, G. (1987), First results from the Airborne Visible/Infrared Imaging Spectrometer (AVIRIS), SPIE, 834, 166-174. 